\title{
Oligosaccharides in infants' faeces
}

\author{
S. BAAR AND H. BICKEL' \\ From the Medical Research Council Industrial Injuries and Burns Research Unit, \\ Birmingham Accident Hospital
}

SYNOPSIS Concentrated faecal extracts from breast and artificially fed infants during the first week of life were examined by paper chromatography. Besides lactose, glucose and galactose, five oligosaccharide spots were detected. Breast-fed infants showed an additional fucose spot. Complete hydrolysis of the individual oligosaccharides showed glucose and galactose always and fucose in two instances. The oligosaccharides are probably similar to those isolated by other workers from colostrum and human milk.

This is a preliminary report.

Recently observed defects of disaccharide absorption in dystrophic infants suggested a more detailed investigation of the carbohydrates found in the faeces of 200 healthy infants. Paper chromatography showed that the faeces of such healthy infants frequently contained, in addition to the expected glucose, galactose, and lactose, a larger number of oligosaccharides and fucose. These substances were found more frequently during the first four weeks of life rather than in later infancy and in breast-fed rather than in artificially fed infants.

Aqueous faecal extracts from mature infants fed on human and cows' milk during the first week of life were deproteinized by positive pressure filtration through semi-permeable membranes and preserved with thymol. Ions were removed either by extraction of the freeze-dried residue with anhydrous pyridine (Malpress and Morrison, 1949) or by treatment with the bicarbonate form of Biodeminrolit (Smith, 1960). Amounts equivalent to $100 \mathrm{mg}$. of wet faeces were applied to Whatman no. 1 filter paper and the chromatograms were run for 44 hours using $\mathrm{N}$ amyl alcohol : pyridine : water $=1: 1: 1$. The reducing carbohydrates were revealed with aniline hydrogen phthalate.

A typical chromatogram is shown in Figure 1. All specimens examined showed varying amounts of lactose, glucose, and galactose. Material from breast-fed infants also gave a distinct fucose spot. Chromatograms from both groups of infants showed six reducing spots with lower motility than lactose. Bate-Smith and Westall (1950) deduced that a logarithmic relationship was to be expected from a homologous series of polymers. Spots 0 to 5 in order

'University Children's Hospital, Marburg/Lahn, Germany.

Received for publication 26 September 1963. of their motility closely obeyed such a relationship, hence suggesting some structural similarity.

Component carbohydrates were identified by elution of the regions corresponding to spots 0 to 6 , followed by two hours' hydrolysis at $100^{\circ} \mathrm{C}$. with $2 \mathrm{~N} \mathrm{H}_{2} \mathrm{SO}_{4}$. The hydrolysates wete adjusted to $p \mathrm{H} 8$

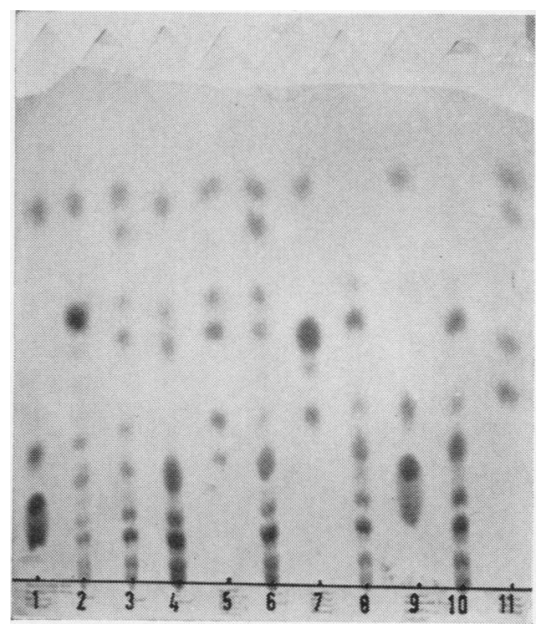

FIG. 1. Oligosaccharides in faecal extracts.

1 Galacturonic acid, glucuronic acid, ribose

2 Faecal extract (3) + ribose

3 Faecal extract (6) + ribose

4 Faecal extract (2) + ribose

5 Raffinose, lactose, galactose, glucose, ribose

6 Faecal extract (1) + ribose

7 Lactose, maltose, sucrose, ribose

8 Faecal extract (4) + ribose

9 Galacturonic acid, glucuronic acid, lactose, ribose

10 Faecal extract (5)

11 Lactose, maltose, fucose, ribose

Case nos. in brackets. Cases 3 and 1 breast fed. 


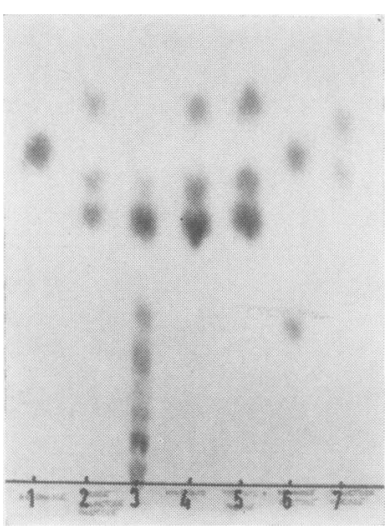

FIG. 2. Comparison of hydrolysed with non-hydrolysed faecal extract.
1 Arabinose
2 Galactose, glucose, fucose
3 Non-hydrolysed extract
4 Hydrolysed extract
5 Hydrolysed extract + fucose
6 Lactose, mannose
7 Fructose, fucose



FIG. 3. Hydrolysate of faecal extract showing pentose spot.

1 Galacturonic acid, glucuronic acid

2 Hydrolysed extract

3 Non-hydrolysed extract

4 Hydrolysed extract

5 Non-hydrolysed extract

6 Galactose, glucose, fucose

7 Lactose, maltose

with $\mathrm{Na}_{2} \mathrm{CO}_{3}$ solution and electrolytically desalted according to Blainey and Yardley (1956). The desalted material was then lyophilized, redissolved in minimal amounts of $\mathrm{H}_{2} \mathrm{O}$, and chromatographed as above. Figure 2 shows a typical chromatogram. All hydrolysates showed the presence of galactose and glucose, but only oligosaccharides 2 and 4 (numbered in terms of their movement from the origin) gave reasonably strong spots of fucose. The additional presence of glucosamine and $\mathrm{N}$ acetyl glucosamine was shown by pooling three hydrolysates and developing in the solvent described above followed by detection with Morgan-Elson reagent. Identity was tentatively established by co-chromatography with marker substances. Hydrolysis for one hour only of more concentrated material showed the presence of an additional spot of characteristic pentose colour as shown in Figure 3. This suggests the presence of hexuronic acids in the original extracts.

An attempt was made to establish the molecular ratios of the hydrolysis products by elution of the spots according to Baar (1954). Duplicate experiments gave the ratios indicated in Table $I$. The relatively low colour intensity of the amino sugar spots suggested the absence of these from some of the component oligosaccharides.

These preliminary findings suggest that the oligosaccharides found in the intestinal contents of young infants bear some structural relationship to those isolated by György, Kuhn, Rose, and Zilliken (1954) from colostrum and human milk in the course of their study of the bifidus factor. Oligosaccharide 5 could well be fucosyl lactose.

TABLE I

\begin{tabular}{|c|c|c|c|c|}
\hline $\begin{array}{l}\text { MOLECUL } \\
\text { Oligosaccharide } \\
\text { No. }\end{array}$ & $\begin{array}{l}\text { AR RATIOS OF } \\
\text { Component } \\
\text { Monosaccharide }\end{array}$ & $\begin{array}{l}\text { PRODUC } \\
\text { E480m }\end{array}$ & $\begin{array}{l}\text { TS OF HYD } \\
u ! \text { Moles }\end{array}$ & $\begin{array}{l}\text { ROLYSIS } \\
\text { Molecular } \\
\text { Ratio } \\
\text { (approximate) }\end{array}$ \\
\hline 0 & $\begin{array}{l}\text { Glucose } \\
\text { Galactose }\end{array}$ & $\begin{array}{l}0.058 \\
0.056\end{array}$ & $\begin{array}{l}62 \\
78\end{array}$ & $1: 1$ \\
\hline 1 & $\begin{array}{l}\text { Glucose } \\
\text { Galactose }\end{array}$ & $\begin{array}{l}0.071 \\
0.078\end{array}$ & $\begin{array}{l}66 \\
75\end{array}$ & $1: 1$ \\
\hline 2 & $\begin{array}{l}\text { Glucose } \\
\text { Galactose } \\
\text { Fucose }\end{array}$ & $\begin{array}{l}0 \cdot 094 \\
0 \cdot 161 \\
0 \cdot 106\end{array}$ & $\begin{array}{r}83 \\
156 \\
126\end{array}$ & $1: 2: 1 \cdot 5$ \\
\hline 3 & $\begin{array}{l}\text { Glucose } \\
\text { Galactose }\end{array}$ & $\begin{array}{l}0.089 \\
0.090\end{array}$ & $\begin{array}{l}78 \\
86\end{array}$ & $1: 1$ \\
\hline 4 & $\begin{array}{l}\text { Glucose } \\
\text { Galactose } \\
\text { Fucose }\end{array}$ & $\begin{array}{l}0.080 \\
0.074 \\
0.080\end{array}$ & $\begin{array}{l}80 \\
72 \\
97\end{array}$ & $1: 1: 1 \cdot 2$ \\
\hline 5 & $\begin{array}{l}\text { Glucose } \\
\text { Galactose }\end{array}$ & $\begin{array}{l}0 \cdot 196 \\
0 \cdot 184\end{array}$ & $\begin{array}{l}206 \\
270\end{array}$ & $1: 1 \cdot 3$ \\
\hline 6 & $\begin{array}{l}\text { Glucose } \\
\text { Galactose }\end{array}$ & $\begin{array}{l}0.063 \\
0.111\end{array}$ & $\begin{array}{r}70 \\
153\end{array}$ & $1: 2$ \\
\hline
\end{tabular}

\section{REFERENCES}

Baar, S. (1954), Biochem, J., 58, 175.

Bate-Smith, E. C., and Westall, R. G. (1950), Biochim. biophys. Acta (Amst.), 4, 427.

Blainey, J. D., and Yardley, H. J. (1956). Nature (Lond), 177, 83. György, P., Kuhn, R., Rose, C. S., and Zilliken, F. (1954). Arch. Biochem. Biophys., 48, 202.

Malpress, F. H., and Morrison, A. B. (1949). Nature (Lond.), 164, 479. Smith, I. (1960). Chromatographic and Electrophoretic Techniques, vol. 1, p. 59. Heinemann, London. 